\title{
Lathosterol and other Noncholesterol Sterols in Treatment of Hereditary Hypercholesterolemias: 20-Year Experience among School Children and Adolescents
}

\author{
Josef Hyánek ${ }^{1,{ }^{*}}$, František Pehal ${ }^{2}$, Ladislava Dubská ${ }^{2}$ Blanka Miková ${ }^{2}$ Věra Martiníková1, \\ Jana Privarová ${ }^{1}$, Jana Brtnová ${ }^{2}$ and Luděk Táborský
}

\author{
${ }^{1}$ Metabolic Centre, and ${ }^{2}$ Department of Clinical Biochemistry, Hematology and Immunology; both $\mathrm{Na}$ \\ Homolce Hospital, Prague, (Nemocnice Na Homolce, Roentgenova 2, 15030 Praha 5), Czech Republic
}

\begin{abstract}
Aims: This paper presents our 20-year experience with diagnosing heterozygous familial hypercholesterolemia (HFH) and monitoring its diet and drug treatment in 94 children (6-18 years) by means of noncholesterol sterols (NCS), namely lathosterol (Lat) and desmosterol (Des) as cholesterol synthesis precursors, and campesterol (Cam) and sitosterol (Sit) as cholesterol absorption precursors.

Patients and Methods: Four groups were included in the study: (1) 64 children with genetically confirmed HFH; (2) 30 children with clinical and laboratory symptoms of HFH where the relevant genetic mutations have not been found; (3) 77 children with alimentary hyperlipidemia (AH), and (4) 84 healthy children as a control group. The followed-up markers were routine lipid profile comprising total cholesterol (TC), low-density lipoprotein cholesterol (LDL-C), high-density lipoprotein cholesterol (HDL-C) and triacylglycerides (TAG), complemented by apolipoprotein A1 (ApoA), apolipoprotein $B(A p o B)$, lipoprotein(a) (Lp(a)), low-density lipoprotein receptor (LDL-R), apolipoprotein E (ApoE) polymorphism, and plasma NCS (Lat, Des, Cam and Sit), the latter being established by means of GC/MS. The medical treatment of HFH patients consisted of simvastatin and ezetimibe. Correlations between TC lowering and decrease in Lat and other NCS values during combination treatment were examined in various types of hypercholesterolemia.

Results: HFH patients, whether genetically confirmed or not, exhibit a significant decrease in Lat (and in milder concentrations also Des) which correlates directly to the TC lowering during the combination therapy $(r=0.912$ for Lat; $r=0.798$ for Des; $p<0.001)$. Cam and Sit do not correlate with the TC lowering at all $(r=-0.378$ for Cam; $r=-0.208$ for Sit). By contrast, high TC levels in AH patients are not accompanied by significantly elevated Lat levels, and, therefore, caloric restriction cannot result in significant Lat or Des decrease $(p<0.001)$. Lat and Des levels are also high following drug treatment interruption during long vacations or when the drug treatment is neglected. Compensatory elevation of Cam and Sit occurs in 50\% of treated children patients after the desirable TC level below $4.8 \mathrm{mmol} / \mathrm{l}$ has been achieved and maintained. In our experience, the combination of statin and ezetimibe is the most efficacious therapy to lower TC together with Lat and Des in children with HFH.
\end{abstract}

Conclusions: Inclusion precursors for cholesterol synthesis and absorption in laboratory testing improve differential diagnosis of $\mathrm{HFH}$, and makes monitoring and/or treatment of pediatric patients more precise and convenient.

Keywords: Noncholesterol sterols, lathosterol, desmosterol, campesterol, sitosterol, phytosterols, heterozygous familial hypercholesterolemia, alimentary hyperlipidemia, monitoring diet and drug treatment, simvastatins, ezetimibe.

\section{INTRODUCTION}

Early identification, differentiation, and treatment of inherited disorders of lipid metabolism in child age allows prevention of adult premature cardiovascular and cerebrovascular conditions. There are at least 3 types of autosomal dominant familial hypercholesterolemia, resulting from: a) the deficient low-density lipoprotein receptor (LDL-R) that cannot bind, internalize or recycle the low-density lipoprotein cholesterol (LDL-C); b) the familial defective apolipoprotein B-100 (FDB; p.Arg3527GIn mutation); or c) a gain-of-function mutation in PCSK9 (p.Asp374Tyr). In the last decade, it came to be finally accepted by the

${ }^{*}$ Address correspondence to this author at the Metabolic Centre, Na Homolce Hospital, Prague (Metabolická poradna OKBHI, Nemocnice Na Homolce, Roentgenova 2, 15030 Praha 5), Czech Republic; Tel: +420 603440 013; E-mail: josef.hyanek@homolka.cz medical community that heterozygous familial hypercholesterolemias (HFH) in children (boys aged 810 , girls after menarche) require the same intensity of medical therapy as in adults [1-6].

However, what makes differential diagnosis and therapy of children more difficult and challenging is the as-yet-undeveloped typical clinical symptoms paired with the requirements of the growing organism. The dietary and especially medical treatment must not endanger the adequate nutritional supply of cholesterol, which is indispensable for the metabolic processes in the growing child's organism. Therefore, we had to complement the standard metabolic markers by additional ones, namely noncholesterol sterols (NCS), in order to make the diagnosis and treatment more efficacious. For practical and methodological purposes, we introduced lathosterol (Lat) and 

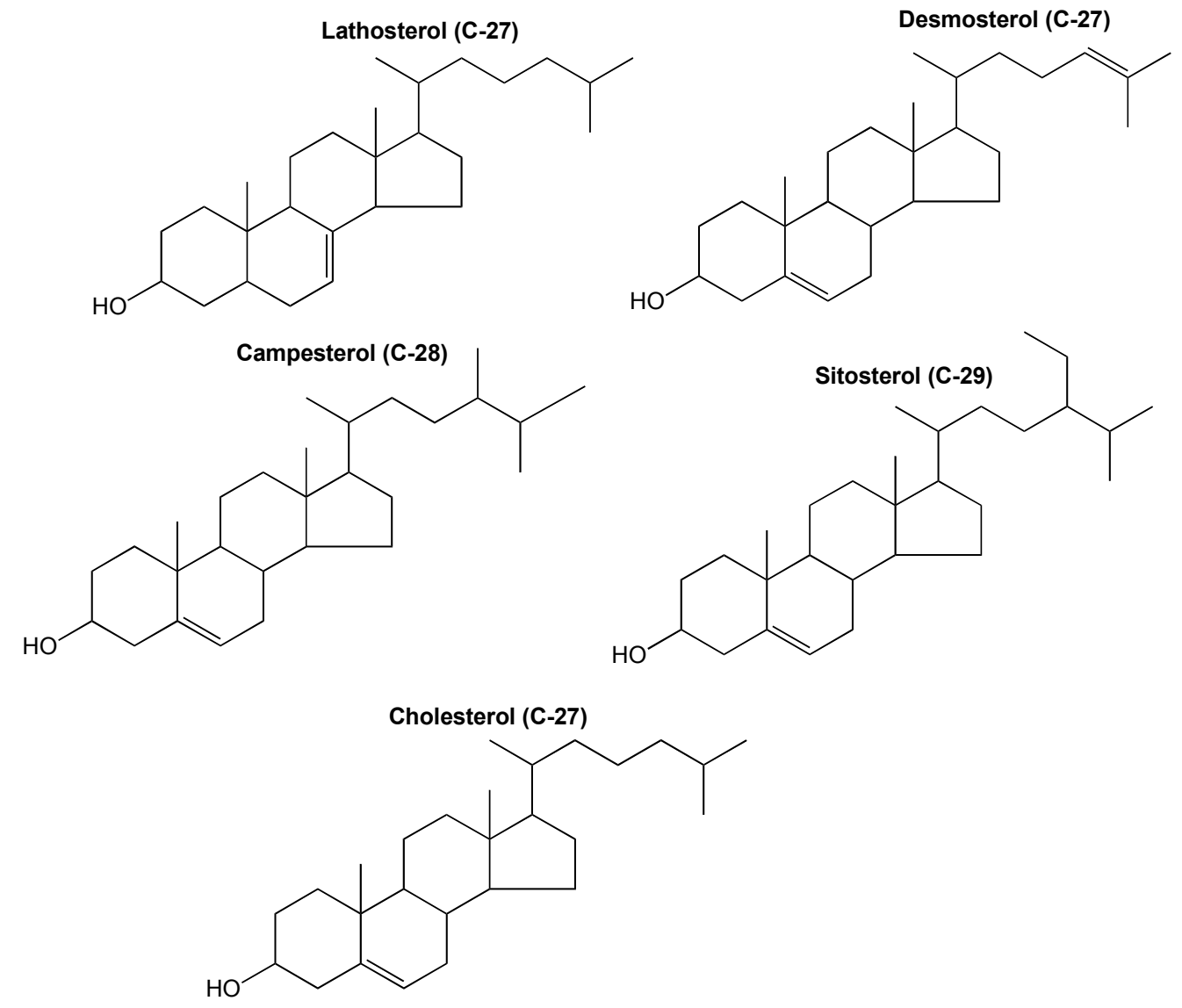

Figure 1: Chemical structures of noncholesterol sterols under discussion and cholesterol.

desmosterol (Des) as cholesterol synthesis markers, and campesterol (Cam) and sitosterol (Sit) as phytosterol absorption markers (Figure 1).

We have now been successfully using these NCS for 20 years (1) to distinguish between $\mathrm{HFH}$ and alimentary hyperlipidemia $(\mathrm{AH})$, the latter being very frequent among the children attending our metabolic centre; and (2) to monitor dietary and/or combination medical (statins and ezetimibe) therapy. Among the large cohort of children and adolescents attending our metabolic centre over the last two decades, 93 patients aged 5-18 years have been classified into various types of HFH depending on their baseline metabolic and genetic findings. This paper presents our 20-year diagnostic and therapeutic experience with these patients. Following the initial skepticism and critical attitudes towards treatment of pediatric patients, we can now rely on the similarly positive experience of other authors gained over the last decade [7-12].

\section{PATIENTS AND METHODS}

The study was approved by the $\mathrm{Na}$ Homolce Hospital Ethics Committee under Project No. NA 7452-
3 supported by the Internal Grant Agency of the Czech Ministry of Health (IGA MZ CR).

\subsection{Patients}

To best demonstrate our clinical experience, this paper compares the data for the following four groups:

HFH-Gen group: 64 pediatric patients with high total cholesterol (TC) levels genetically confirmed by an LDL-R or FDB mutation, and a positive family history of CVD (Framingham Risk Score $10-20 \%$ ), who were treated by combined drug therapy (boys starting at age 10 years, girls after menarche).

HFH-Sympt group: 30 pediatric patients with high TC levels and a positive family history of $\mathrm{HFH}$ including premature cardiovascular disease (CVD), but without genetic confirmation of the diagnosis, who receive the same medication as HFH-Gen group.

AH group: 77 pediatric patients with confirmed alimentary hyperlipidemia, where a mild TC elevation is accompanied by variously 
manifested hypertriglyceridemia ( $>5 \mathrm{mmol} / \mathrm{l})$ and mild obesity.

$>\quad$ Healthy group: 84 healthy children aged 6-18 years from Prague schools as controls.

\subsection{Methods}

The routine biochemistry and standard lipid profile (TC - colorimetric assay, HDL-C - immunoassay, LDLC - direct immunoassay, TAG enzymatically) were measured with a Synchron Beckman Coulter LX 20; haematology profile by means of an Advia 120 Bayer; apoA and apoB nephelometrically using an Image; apoE polymorphism was determined by molecular genetic analysis; sexual hormone levels were measured by IRMA with a Stratec SR300; trace elements with a GT-AAS Varian; lipid soluble vitamins by means of HPLC with UV detection; vitamin D3 by the RIA technique with a Multicrystal Berthold LB211; vitamin B6 using a Chromsystem; holotranscobalamin with an Abbot AXIM; and beta-carotene by means of HPLC.

Genetic testing for LDL-R and FDB mutations consisted of direct DNA analysis, sequence analysis of exon 4 and 5 , and screening for deletions and duplications of the LDL-R gene by Multiplex Ligation Probe Amplification method, which was carried out by the courtesy of Prof. Tomás Freiberger, PhD., the Czech national coordinator of the international MedPed (Make Early Diagnosis to Prevent Early Deaths in Medical Pedigrees) project based at the Molecular Genetics Laboratory, Centre for Cardiovascular and Transplantation Surgery, Brno [18, 19]. Initiated in 2014, the current diagnostic scheme is based primarily on next generation sequencing for all exons (and adjacent intronic junctions) of the LDL-R and the PCSK9 genes and partial sequencing of the ApoB gene. The first degree relatives of HFH probands with identified gene mutations undergo DNA sequencing regardless of the plasma LDL-C levels.[20]).

The plasma NCS (see Figure 1) were initially determined using Gas Chromatography following Phillips et al. [21], and later via the Theunissen [22] modification by means of a GC/MS Finnigan Mat 120b with epicholesterol applied as an internal standard, CV $<10 \%$. According to our long-term practical experience with NCS level assessment, Des follows Lat in lower concentrations, and Sit follows Cam values in a similar way. For practical purposes, the NCS values are given in $\mu \mathrm{mol} / \mathrm{l}$ throughout this paper.
Statistical analysis was performed using MedCalc, Version 8.1.1.1 (Belgium). The basic statistical parameters included confidence intervals for the mean nor median at a 95 percent confidence level, sample size, maximum and minimum values, and the respective standard deviations. Normality was assessed using the D'Agostino-Pearson test. Correlation analysis between NCS and TC during the combined treatment was performed using Spearman's coefficient. The paired t-test was used to compare the two independently established mean values of NCS and lipid metabolites during treatment. The difference was significant with values $<0.05$.

The alimentary hyperlipidemia diagnosis was based on the lipid profile evaluation, pedigree analysis, low risk of CVD, and assessment of a submitted twoweek food journal, which was analyzed for nutrient content and cholesterol intake (mg per day) by the Ostrasoft Co. software program (2002) [12].

The low cholesterol diet (LCD, in Figures referred to as LCHD) was defined as the 1992 National Cholesterol Education Program (NCEP) CHILD-2 diet (<300 mg/d dietary cholesterol) [13].

The HFH drug treatment involves administration of simvastatin-Zocor (MSD) or rosuvastatin-Rosumop (Sandoz) or Rosucard (Zentiva) in individual doses of $5-20 \mathrm{mg}$ daily, in combination with ezetimibe-Ezetrol (MSD) in individual doses of $5-10 \mathrm{mg}$ daily [2-4, 15, 16]. The decision-making and therapy initiation process takes at least 6 months and is specifically tailored for each patient depending on (a) the family history of CVD (b) the results of genetic testing, (c) the patient's response to medication, and (d) verified compliance and achieved TC levels. As recommended by Wiegman, deJongh, McCrindle, and Rifkind [2, 3, 11, 14], TC levels should be kept consistently below 4.8 $\mathrm{mmol} / \mathrm{l}$ in patients predisposed to CVD.

\subsection{Diagnosis and Treatment Pattern}

The diagnosis and decision-making on the therapy of pediatric patients presenting to our metabolic centre with high TC levels typically unfold in the following manner:

At the $\mathbf{1}^{\text {st }}$ (entry) visit, the patient is without treatment. Blood cholesterol, Lat, and other NCS levels are reassessed to inform treatment decisions and estimate its psychological effect on the family. Genetic consultation may be recommended for assessment of 


\begin{tabular}{|c|c|c|}
\hline 1st Visit & $\begin{array}{l}\text { Findings for HFH: } \\
\text { TC }>5.0 \mathrm{mmol} / \mathrm{I} \\
\text { Lat }>5 \mu \mathrm{mol} / \mathrm{I} \\
\text { TAG<3 mmol// } \\
\text { CVD Risk and Pedigree: ++ } \\
\text { diagnosed as HFH } \\
\text { Therapy: } \\
\text { Ezetimibe } 10 \mathrm{mg} / \mathrm{d} \\
\text { Healthy Life Style + Sporting } \\
\text { LCD Check-Up } \\
\text { Genetic Consultation for Family }\end{array}$ & $\begin{array}{l}\text { Findings for AH: } \\
\text { TC<5 mmol// } \\
\text { Lat }<5 \mu \mathrm{mol} / / \\
\text { TAG }>3.5 \mathrm{mmol} / \mathrm{I} \\
\text { CVD Risk + Pedigree: } 0 \\
\text { diagnosed as AH } \\
\text { Therapy: } \\
\text { Calorie Restriction } \\
\text { Healthy Life Style + Sporting }\end{array}$ \\
\hline 2nd Visit & $\begin{array}{l}\text { if TC }>4.8 \mathrm{mmol} / \mathrm{I} \& \text { Lat }>5 \mu \mathrm{mol} / \mathrm{l} \\
\text { Therapy: } \\
\text { Ezetimibe + Statin } 10 \mathrm{mg} / \mathrm{d}\end{array}$ & $\begin{array}{l}\mathrm{TC}<4,8 \mathrm{mmkol} / \mathrm{l} ; \text { Lat }<5 \mathrm{nmol} / \mathrm{l} ; \\
\mathrm{TAG}<1,8 \mathrm{mmol} / / \\
\text { Therapy:Calorie Restriction }\end{array}$ \\
\hline 3rd Visit & $\begin{array}{l}\text { if TC }>4.8 \mathrm{mmol} / \mathrm{I} \& \text { Lat }>5 \mu \mathrm{mol} / \mathrm{l} \\
\text { Therapy: } \\
\text { Ezetimibe + Statin } 20 \mathrm{mg} / \mathrm{d}\end{array}$ & \\
\hline 4th Visit & $\begin{array}{l}\text { TC }<4.8 \mathrm{mmol} / \mathrm{I} \& \text { Lat }<3.8 \mu \mathrm{mol} / \mathrm{l} \\
\text { Therapy: } \\
\text { Continuation of Selected Doses }\end{array}$ & \\
\hline
\end{tabular}

Figure 2: Typical diagnosis and treatment pattern followed by children presenting to Metabolic Centre.

the patient's siblings, depending on the pedigree. In the case of an HFH positive result, the patient will be typically prescribed $10 \mathrm{mg}$ of ezetimibe daily for a period of 1 to 2 months till the next visit.

At the $2^{\text {nd }}$ visit blood tests are repeated to determine the effectiveness of the ezetimibe therapy, and if the desired TC lowering has not been achieved, $5-10 \mathrm{mg}$ of statin daily is combined with ezetimibe for the following 1 to 2 months;

If the TC levels still exceed $4.8 \mathrm{mmol} / \mathrm{l}$ at the $3 \mathrm{rd}$ visit and Lat has not been significantly lowered, the dose of statin is increased to $15-20 \mathrm{mg}$ daily depending on the cholesterol tolerance.

The $4^{\text {th }}$ visit follows after another 3 months to check that the TC has dropped below $4.8 \mathrm{mmol} / \mathrm{l}$.

The typical diagnosis and treatment decisionmaking pattern followed in our Metabolic Centre is summarized in Figure 2, which also demonstrates the differentiated therapeutic approach to $\mathrm{HFH}$ and $\mathrm{AH}$ patients.

After 1 year the combination drug therapy is interrupted for 1 to 2 months during school summer holiday to test cholesterol tolerance, detect its maximum achieved level and possibly reduce the medication. The patients are usually not available for monitoring in summer, and their compliance with the drug therapy is often lowered. The dietary therapy is not to be discontinued over this period (for more methodical details see references, $[16,17])$.

\section{RESULTS}

The basic initial characteristics of the investigated children groups (age, gender, skin fold, and mean values for TC, LDL-C, and ApoB) are shown in Table $1 \mathrm{a}$.

Table 1b shows baseline lipid laboratory markers and their values for the individual study groups.

Table 2 is an overview of the gene mutations identified in the HFH-Gen patients.

Figures 3, 4 and 5 document monitoring of TC and NCS levels in three different subgroups of the HFH children patients at individual visits: (1) 25 selected $\mathrm{HFH}-$ Gen patients with the highest TC levels and most severe LDL-R mutations (Figure 3); (2) the $16 \mathrm{HFH}$ Gen patients with FDB gene mutation (Figure 4); and 
Table 1a: Basic Initial Characteristics of Study Groups

\begin{tabular}{|c|c|c|c|c|c|c|}
\hline & Age $(\mathbf{y r s})$ & Male/Female & Skin Fold (mm) & TC (mmol/l) & LDL-C (mmol/l) & ApoB (g/l) \\
\hline \hline HFH-Gen $(n=64)$ & 6 to 18 & $33 / 31$ & $5.5 / 10.2 / 8$ & $6.1 \pm 3.2$ & $4.5 \pm 2.1$ & $2.6 \pm 1.8$ \\
\hline HFH-Sympt $(n=30)$ & 6 to 18 & $13 / 17$ & $5.5 / 10.2 / 8$ & $5.6 \pm 1.8$ & $3.9 \pm 2.5$ & $2.5 \pm 1.6$ \\
\hline AH $(n=77)$ & 6 to 18 & $20 / 30$ & $6.2 / 12.2 / 10$ & $6.0 \pm 1.5$ & $3.92 \pm 2.1$ & $1.6 \pm 0.3$ \\
\hline Healthy $(n=84)$ & 6 to 18 & $32 / 52$ & $4.2 / 8.5 / 7.5$ & $3.7 \pm 1.5$ & $2.9 \pm 1.0$ & $1.2 \pm 0.8$ \\
\hline
\end{tabular}

Table 1b: Baseline Lipid Profile, ApoB, Lp(a) and NCS Values for Groups under Investigation

\begin{tabular}{|c|c|c|c|c|}
\hline & HFH-Gen $(n=64)$ & HFH-Sympt $(n=30)$ & $\mathrm{AH}(n=77)$ & Healthy $(n=84)$ \\
\hline $\mathrm{TC}(\mathrm{mmol} / \mathrm{l})$ & $6.1 \pm 3.2$ & $5.6 \pm 1.8$ & $6.0 \pm 1.5$ & $3.7 \pm 1.5$ \\
\hline LDL-C (mmol/l) & $4.5 \pm 2.1$ & $3.9 \pm 2.5$ & $3.92 \pm 2.1$ & $2.9 \pm 1.0$ \\
\hline non-HDL-C (mmol/l) & $5.0 \pm 2.0$ & $4.5 \pm 1.8$ & $3.2 \pm 2.1$ & not detected \\
\hline HDL-C (mmol/l) & $1.6 \pm 0.8$ & $1.5 \pm 0.9$ & $1.7 \pm 1.7$ & $2.2 \pm 1.5$ \\
\hline TAG (mmol/l) & $2.8 \pm 1.8$ & $3.1 \pm 1.6$ & $7.2 \pm 7.5$ & $1.2 \pm 0.5$ \\
\hline ApoB $(g / l)$ & $2.6 \pm 1.8$ & $2.5 \pm 1.6$ & $1.6 \pm 0.3$ & $1.2 \pm 0.8$ \\
\hline $\mathrm{Lp}(\mathrm{a})(\mathrm{mmol} / \mathrm{l})$ & $450 \pm 220$ & $380 \pm 180$ & not detected & not detected \\
\hline Lat $(\mu \mathrm{mol} / \mathrm{l})$ & $12.1 \pm 4.6$ & $8.1 \pm 4.2$ & $5.1 \pm 0.8$ & $4.8 \pm 0.45$ \\
\hline Des $(\mu \mathrm{mol} / \mathrm{l})$ & $6.5 \pm 3.2$ & $6.4 \pm 2.1$ & $4.9 \pm 1.5$ & $2.6 \pm 0.25$ \\
\hline Camp $(\mu \mathrm{mol} / \mathrm{l})$ & $7.5 \pm 4.7$ & $8.0 \pm 6.1$ & $8.2 \pm 4.7$ & $9.3 \pm 1.9$ \\
\hline Sit $(\mu \mathrm{mol} / \mathrm{l})$ & $6.9 \pm 4.5$ & $8 \pm 3.2$ & $6.1 \pm 3.6$ & $6.3 \pm 1.5$ \\
\hline
\end{tabular}

Table 2: Distribution of Gene Mutations within HFH-Gen Group

\begin{tabular}{|c|c|c|c|c|}
\hline Gene & Mutation & Boys & Girls & Total \\
\hline \multirow[t]{14}{*}{ LDL-R } & p.Arg 416 Trp & 2 & 0 & 2 \\
\hline & p.Asp.492 Asn & 1 & 0 & 1 \\
\hline & p.Asp.266 Glu & 3 & 0 & 3 \\
\hline & p.Cys.276X & 0 & 1 & 1 \\
\hline & c. $1845+1 G>T$ & 1 & 3 & 4 \\
\hline & C940_940+14del & 0 & 3 & 3 \\
\hline & p.Glu 317X & 1 & 0 & 1 \\
\hline & p.Gly 592 Glu & 4 & 4 & 8 \\
\hline & c. $1751 \mathrm{delC}$ & 0 & 2 & 2 \\
\hline & c.98 delG & 1 & 1 & 2 \\
\hline & c.896delC & 0 & 2 & 2 \\
\hline & p.His 690 Thrfs X19 & 4 & 3 & 7 \\
\hline & p.Ser306 X & 1 & 0 & 1 \\
\hline & Pro424_Asn425ins32 & 2 & 2 & 4 \\
\hline \multirow[t]{2}{*}{ PCSK9 } & & 0 & 0 & 0 \\
\hline & TOTAL & 33 & 31 & 64 \\
\hline
\end{tabular}




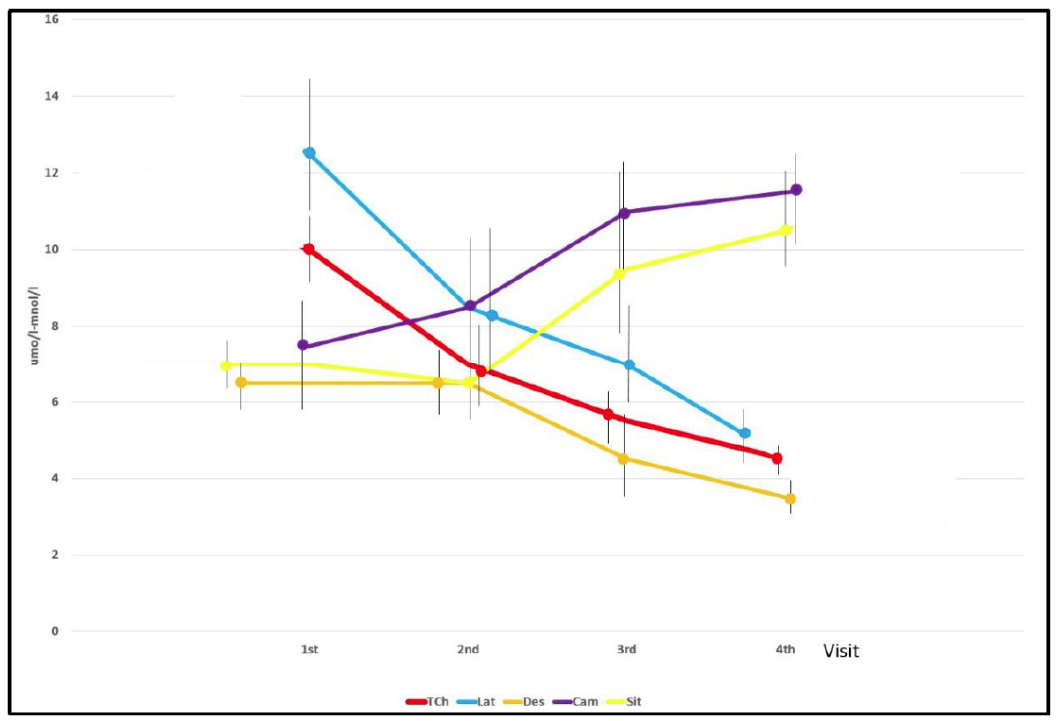

Figure 3: Monitoring of TC and NCS levels in 25 selected HFH-Gen patients with highest TC levels and most severe LDL-R mutations responsible for reduced promotor activity and accompanied by $80-90 \%$ decrease in functional action (c.-153C $>\mathrm{T}$, c.-149C>A and c.-140C>A): p.Cys276X, p.Ser306X, p.His690Thr, p.Cys209Tyr, p.Glu317X, Pro424_Asn425ins32).

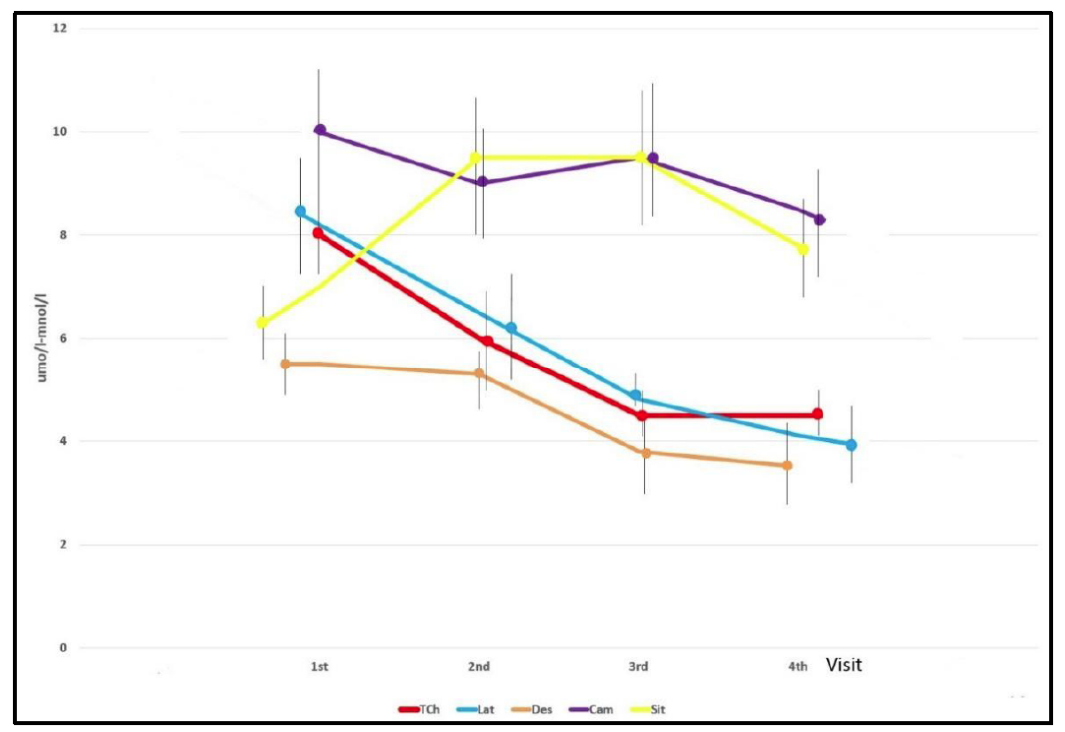

Figure 4: Monitoring of TC and NCS levels in the $16 \mathrm{HFH}-$ Gen patients with FDB gene mutation (p.Arg3527GIn).

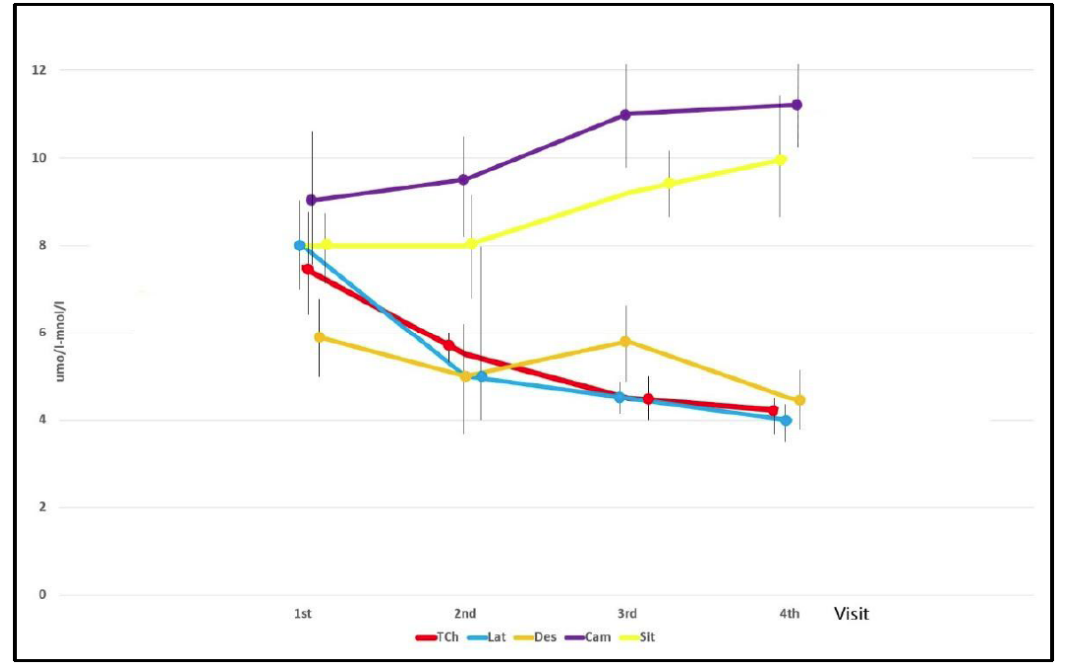

Figure 5: Monitoring of TC and NCS levels in 25 selected HFH-Sympt patients with highest TC levels. 


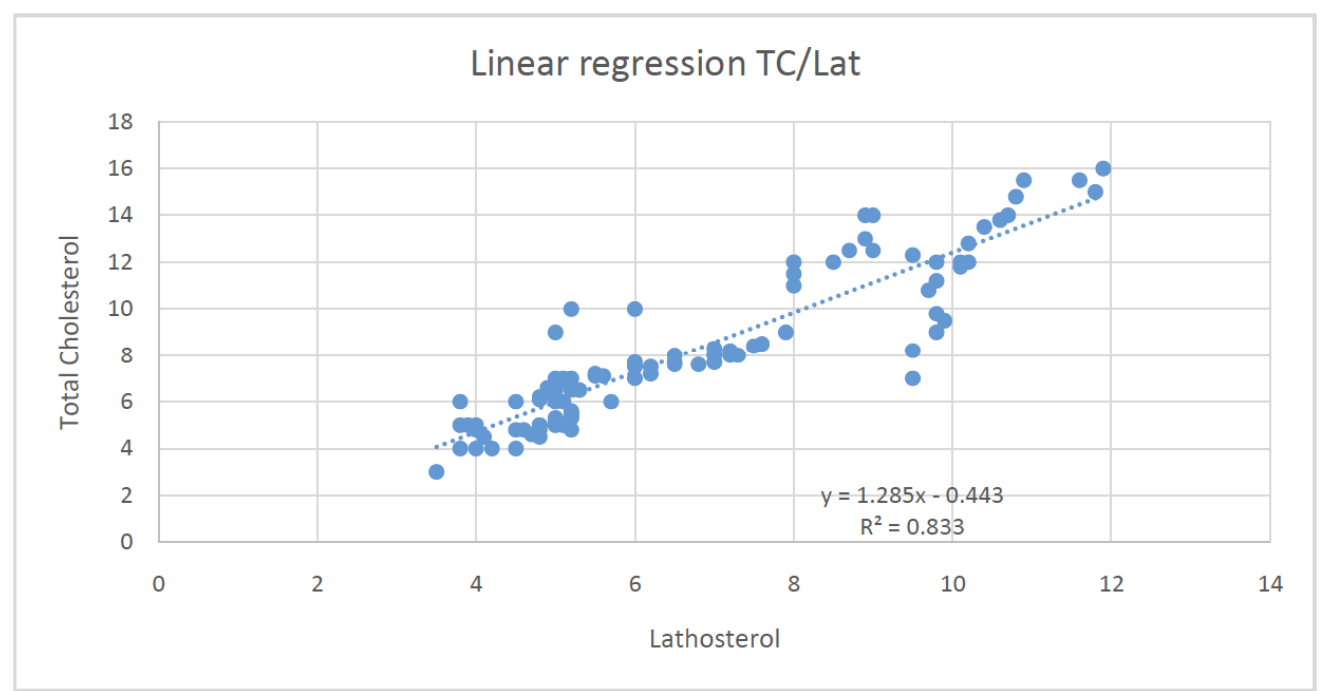

Figure 6: Linear regression for TC and Lat in 25 selected HFH-Gen patients with highest TC levels and most severe LDL-R mutations.

Table 3: Correlation Coefficients for TC and NCS in 25 Selected HFH-Gen Patients with Highest TC Levels and Most Severe LDL-R Mutations

\begin{tabular}{|c|c|c|c|c|c|}
\hline & TC & Lat & Des & Sit & Cam \\
\hline $\mathrm{TC}$ & $x$ & 0.91286 & 0.79879 & -0.28292 & -0.37634 \\
\hline Des & 0.79879 & 0.8634 & $x$ & -0.1425 & -0.0957 \\
\hline Sit & -0.2829 & -0.1377 & -0.1425 & $x$ & 0.8893 \\
\hline
\end{tabular}

(3) 25 selected HFH-Sympt patients with the highest TC levels (Figure 5).

All $\mathrm{HFH}$ patient groups exhibited a positive correlation between the decrease in Lat and lowering of TC in response to the combination drug therapy. The decrease differs depending on the gene mutation, being most distinct in the $25 \mathrm{HFH}-\mathrm{Gen}$ patients with the most severe LDL-R gene mutations (Figures 3, 6, Table 3).
The correlation between TC and Lat is slightly less marked but equally significant in the 16 FDB patients (Figure 4, Table 4), and less significant in the $25 \mathrm{HFH}$ Sympt patients (Figure 5, Table 5). The change is most pronounced in Lat, Des decrease is smaller but also significant. The compensatory elevation in Cam and Sit occurs in half of the patients after the combination therapy has been initiated and the TC levels have dropped below $4.8 \mathrm{mmol} / \mathrm{l}$. The change is again most pronounced in the $25 \mathrm{HFH}-\mathrm{Gen}$ patients with the most

Table 4: Correlation Coefficients for TC and NCS in in the 16 HFH-Gen Patients with FDB Gene Mutation (p.Arg3527GIn)

\begin{tabular}{|c|c|c|c|c|c|}
\hline & TC & Lat & Des & Sit & Cam \\
\hline \hline TC & $\mathrm{x}$ & 0.9288 & $0.6963 \mathrm{x}$ & 0.0025 & 0.5646 \\
\hline Lat & 0.9288 & $\mathrm{x}$ & 0.7943 & 0.1181 & 0.5578 \\
\hline Des & 0.696 & 0.7943 & $\mathrm{x}$ & $\mathrm{x}$ & 0.4283 \\
\hline Sit & 0.0025 & 0.1181 & 0.406 & 0.5423 & $\mathrm{x}$ \\
\hline Cam & 0.5646 & 0.5578 & 0.4283 & 0.5423 \\
\hline
\end{tabular}


Table 5: Correlation Coefficients for TC and NCS in 25 Selected HFH-Sympt Patients with Highest TC Levels

\begin{tabular}{|c|c|c|c|c|c|}
\hline & TC & Lat & Des & Sit & Cam \\
\hline \hline TC & $x$ & 0.896 & 0.0505 & 0.173 & 0.4646 \\
\hline Lat & 0.896 & $x$ & 0.6247 & 0.4139 & 0.6567 \\
\hline Des & 0.0505 & 0.6247 & $x$ & 0.6844 & 0.5285 \\
\hline Sit & 0.173 & 0.4139 & 0.6844 & 0.6433 & $x$ \\
\hline Cam & 0.4656 & 0.6567 & 0.5285 & 0.6433 \\
\hline
\end{tabular}

severe LDL-R mutations. In HFH-Sympt patients, the compensatory phytosterol effect is less marked.

Combination drug treatment by statin and ezetimibe has to date produced the most effective decrease in Lat and Des along with lowering of TC, while phytosterol levels (Cam and Sit) have not been significantly changed.

LCD has practically no impact on the Lat and Des decrease. In nearly half of patients, LCD is accompanied by elevated phytosterol levels, which, however, are due to compensatory cholesterol absorption in the intestine or seem to be accentuated by increased intake of stanol esters from margarine enriching LCD with plant sterols, such as Benecol (Raisio Group) and FloraPlus (Unilever).

Figure 7 shows the insignificant NCS level changes in 25 selected $\mathrm{AH}$ patients treated by calorie restriction and changed lifestyle.

For the sake of completeness, Figure 8 shows a typical correlation between TC and NCS levels in response to different therapeutical approaches in an FDB homozygous female adolescent.

The dynamics of effective TC lowering in response to combination drug treatment can be checked during school summer holiday by interrupting medication as shown in Figure 9. This helps us identify agedependent changes in dietary cholesterol tolerance where "tracking effect" does not apply. It is necessary to note that almost $30 \%$ of $\mathrm{HFH}$ female adolescents increase their cholesterol tolerance as a result of hormonal maturing when their period becomes regular, and their medication must be properly adjusted or even discontinued [23].

\section{DISCUSSION}

The incidence of $\mathrm{HFH}$ in the Czech population is relatively high (1 to 250-300) and similar to neighbouring Slavic countries. Currently, the most frequently identified gene mutation is FDB (p.Arg3527Gln) followed by p.(Gly592Glu), p.(Asp266Glu) and p.Arg416Trp. [20]. Treatment of

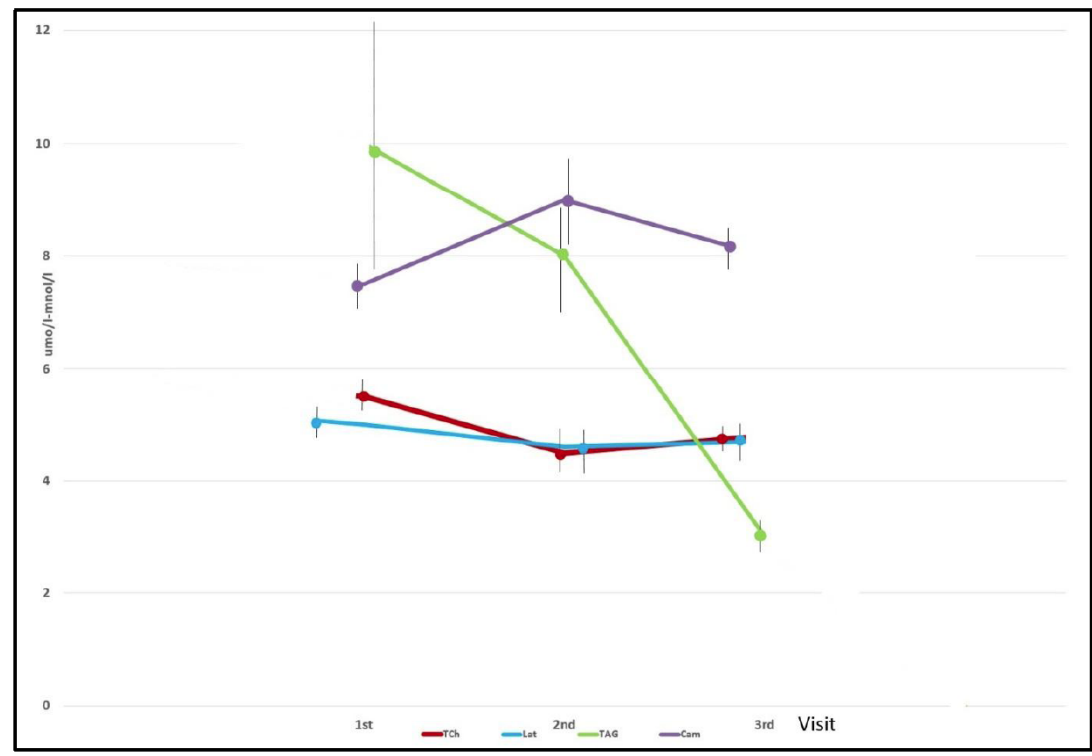

Figure 7: Monitoring of TC and NCS levels in 25 selected AH patients. 


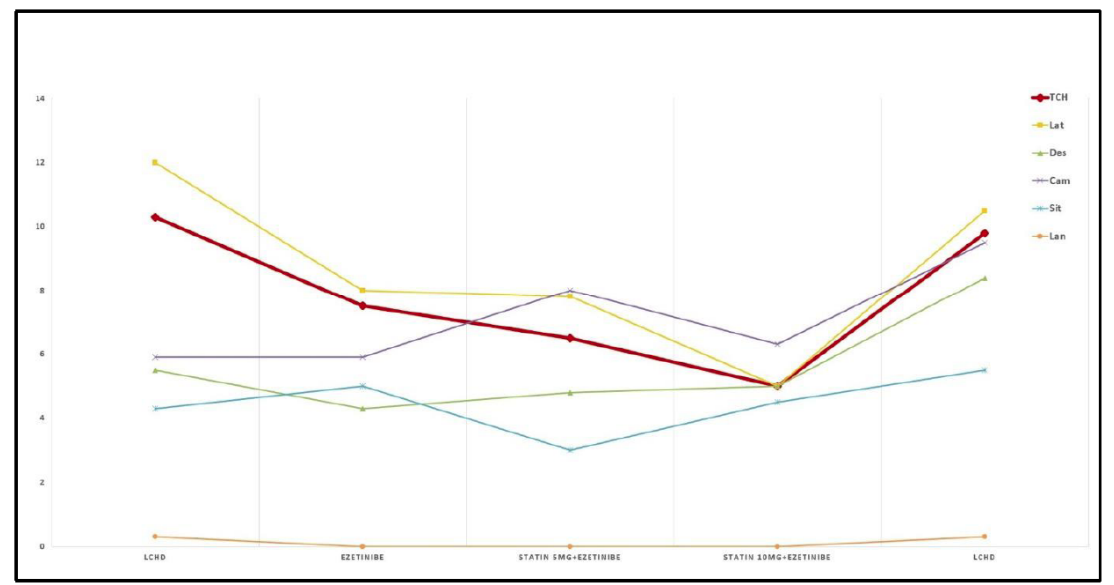

Figure 8: Monitoring dynamics of TC and NCS levels in response to different therapeutical approaches in a FDB homozygous female adolescent.

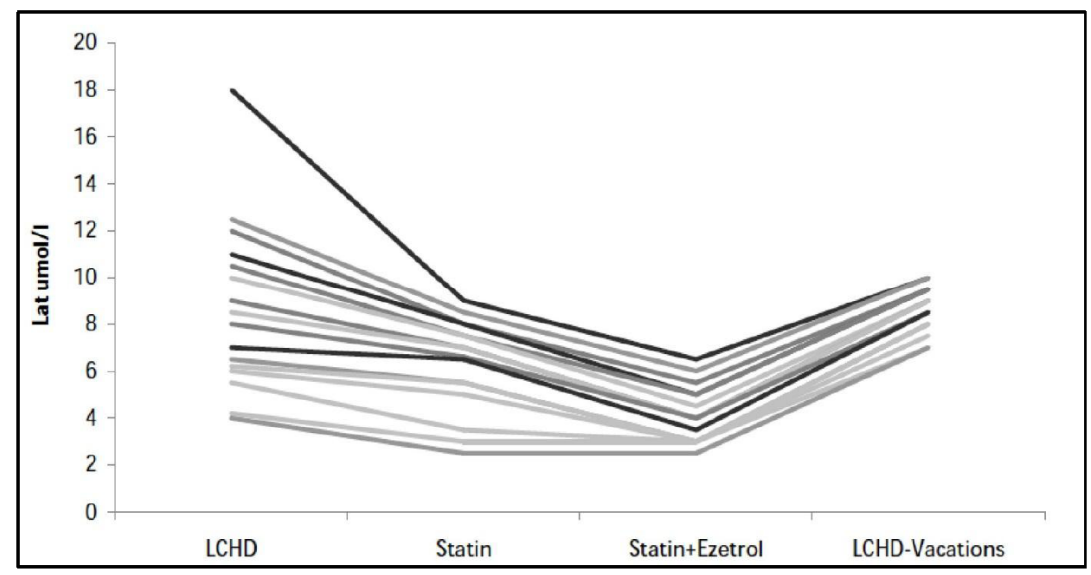

Figure 9: Summary of Lat changes in HFH patients undergoing different types of therapy including medical therapy discontinuation during summer school holiday.

such a large number of patients requires a sophisticated system of diagnostic and therapeutic care provided for in the Czech Republic in an exemplary manner by the MedPed network. Each pediatrician is aware of the absolute necessity to comply with the $\mathrm{HFH}$ therapy in collaboration with the ill child's parents in the absence of another treatment efficacy indicator to properly assess the necessity or effectiveness of medical treatment.

Extension of the lipid panel by such markers as NCS allows more precise monitoring of essential blood cholesterol during combination treatment as well as better insight into the metabolic changes in a growing child or undisciplined adolescent. This reduces the risk of reduced growth and protein deficiency formerly seen in children whose parents and grandparents were trying to protect them from premature CVD by application of too strict LCD. On the other hand, we also encounter gullible parents and typically grandmothers coming to our metabolic centre with overfed children suffering from alimentary hyperlipidemias (TC and TAG levels of 8-12 $\mathrm{mmol} / \mathrm{l}$ ), who only follow television advertising or clamorous leaflets offering "guaranteed" dietary products. Here, NCS may be instrumental in checking whether such children receive plant sterol esters in their diet.

Only 6 patients with confirmed LDL-R gene mutations and 3 patients with confirmed FDB mutation $(=10 \%)$ failed to exhibit a significant correlation between TC and Lat decrease during therapy, or their baseline Lat levels were not sufficiently elevated to produce significant lowering in response to treatment. This group of patients will require our further attention.

Given the existence of around 1,000 known LDL-R mutations with different functional capacities for cholesterol internalization (from 5 to 70\%) and also given the proven influence of other metabolic risk 
factors, such as high Lp (a)>1000 mg/l, or adverse polymorphism of apoE $3 / 4$ and $4 / 4$, it is not at all surprising to find such a wide range of hypercholesterolemic patients responding diversely to any treatment. Therefore, it is necessary to share, compare and expand the practical experience, standardize the testing and verify the observations made by others authors who have discovered and benefited from the diagnostic value of NCS [24-29].

\section{CONCLUSION}

Following up on our first report more than a decade ago [12], we can now confirm on a larger group of children that the decreasing TC levels during the combined drug treatment of $\mathrm{HFH}$ directly correlate with the decrease in Lat, which is of invaluable practical use to us $[16,17]$. Considering this methodology as highly practical, effective and routinely available these days, we recommend it for wider use in pediatric hypercholesterolemic patients. We have very good long-term experience with the use of NCS in (a) differentiating between $\mathrm{HFH}$ and $\mathrm{AH}$; (b) monitoring the medication efficacy (monotherapy vs. combined therapy) ; (c) determining the size of therapeutic statin doses; and d) checking the current intake of plant sterol-enriched foods.

\section{ABBREVIATIONS}

$\mathrm{AH}=$ alimentary hyperlipidemia

$\mathrm{ApoB}=$ apolipoprotein $\mathrm{B}$

Cam $=$ campesterol

CVD = cardiovascular disease

Des $=$ desmosterol

$\mathrm{FDB}=$ familial ligand- defective apoB 100

HDL-C = high density lipoprotein cholesterol

$\mathrm{HFH}=$ heterozygous familial hypercholesterolemia

GC/MS = gas chromatography/mass spectrometry

IMT = intima media thickness

Lat $=$ lathosterol

LCD = low-cholesterol diet

LDL-C = low density lipoprotein cholesterol

LDL-R = LDL-cholesterol receptor
$\operatorname{Lp}(\mathrm{a})=$ lipoprotein $(\mathrm{a})$

NCEP $=$ National Cholesterol Education Program (USA)

NCS $=$ noncholesterol sterols

Sit $\quad=$ sitosterol

TAG = triacylglycerols

$\mathrm{TC}=$ total cholesterol

\section{REFERENCES}

[1] Avis HJ, Hutten BA, Gagné V, et al. Efficacy and safety of rosuvastatin therapy for children with familial hypercholesterolemia. J Am Coll Cardiol 2010; 55: 1121-26. https://doi.org/10.1016/j.jacc.2009.10.042

[2] Wiegman A, Hutten BA, deGroot E, et al. Efficacy and safety of statin therapy in children with familial hypercholesterolemia: a randomized controlled trial. JAMA 2004; 292: 331-337. https://doi.org/10.1001/jama.292.3.331

[3] deJongh S, Ose L, Szamosi T, Gagne C, Lambert M, et al. Efficacy and safety of statin therapy in children with familial hypercholesterolemia: a randomized, double-blind, placebo controlled trial with simvastatin. Circulation 2002; 106: 2231 37. https://doi.org/10.1161/01.CIR.0000035247.42888.82

[4] Gauer R. Hyperlipidemia treatment in children:The younger, the better. Am Family Physician 2010; 82: 462-477.

[5] Bogsrud MP, Langslet G, Wium C, et al. Treatment goal attainment in children with familial hypercholesterolemia:a cohort study of 302 children in Norway. J Clin Lipidol 2017. https://doi.org.10.1016/j.jact2017.11.009

Expert panel on integrated guidelines for cardiovascular health and risk reduction in children and adolescents. Pediatrics, 2011, S 213-S256.

[7] Noto D, Cefalu ABC, Barraco $G$, et al. Plasma noncholesterol sterols: a useful diagnostic tool in pediatric hypercholesterolemia. Pediatr Res 2010; 67: 200-204. https://doi.org/10.1203/PDR.0b013e3181c8f035

[8] Hedman M, Miettinen TA, Gylling H, Ketomäki A, Antikainen $M$. Serum noncholesterol sterols in children with heterozygous familial hypercholesterolemia undergoing pravastatin therapy. J Pediat 2006; 148: 241-246. https://doi.org/10.1016/j.jpeds.2005.08.068

[9] Nissien MJ, Miettinen TE, Gylling $H$, Miettinen TA. Applicability of noncholesterol sterols in predicting response in cholesterol metabolism to simvastatin and fluvastatin treatment among hypercholesterolemic men. Nutr Metab Cardiovasc Dis 2010; 20: 308-316.

https://doi.org/10.1016/j.numecd.2009.04.014

[10] Rodenburg J, Wissers MN, Wiegmasn A, et al. Statin treatmen tin children with familial hypercholesterolemia: a ranadomized controlled trial. JAMA 2004; 292: 331-37. https://doi.org/10.1001/jama.292.3.331

McCrindle BW, Urbina EM, Dennison BA, et al. Drug therapy of high-risk lipid abnormalities in children and adolescents: a specific statement from the American Heart Association Atherosclerosis, Hypertension and Obesity in Youth Committee, Council of Cardiovascular Disease in the Young, with the Council on Cardiovascular Nursing. Circulation 2007; 115: 1948-67.

https://doi.org/10.1161/CIRCULATIONAHA.107.181946 
[12] Hyanek J, Martinikova V, Matoska V, et al. 10years experience with medical treatment of familial hypercholesterolemia in children and adolescents. Českoslov. pediatrie 2006; 61: 404-412, (in Czech with English summary).

[13] NCEP Expert panel of blood cholesterol levels in children and adolescents.National Cholesterol Education Program(NCEP):Highlights of the Report of the Expert Panel on Pediatrics 1992; 89: 495-501.

[14] Rifkind BM, Segal P. Lipid research clinic program reference values for hyperlipidemia and hypolipidemia. JAMA 1983; 250: $1869-1872$. https://doi.org/10.1001/jama.1983.03340140039025

[15] Clauss S, Wai KM, Kavey RW, Kuehl K. Ezetimibe treatment of pediatric patients with hypercholesterolemia. J Pediat 2009; 154: 869-872.

https://doi.org/10.1016/j.jpeds.2008.12.044

[16] Hyanek J, Pehal F, Dubska L, et al. Lathosterol and noncholesterol sterols in routine use for the differentiation andmonitoring of dietary and drug induced treatment of hypercholesterolemias in children and adolescents. JNT 2014; 3: 1-12.

[17] Hyanek J. Serum non-cholesterol sterols in differentiation and treatment of children suffering from hypercholesterolemias; Chapter VI. In Phytosterols-Food Sources, Functions and Health Benefits (Ed. D. Garner), Progress in Food Science and Technology. NOVA's website 2015; pp. 97-116.

[18] Francova H, Trbusek M, Zapletalova $\mathrm{P}$, et al. New promoter mutations in the low-density lipoprotein receptor gene which induced familialhypercholesterolemia phenotype. Molecular and functional analysis. J Inher Metab Dis 2004; 27: 523-28. https://doi.org/10.1023/B:BOLI.0000037337.93335.c4

[19] Tichy L, Fajkusova L, Zapletalova $\mathrm{P}$, et al. Molecular genetic backgraund on an autosomal dominant hypoercholessterolemia in the Czech Republic Physiol Res 2017; 66(Suppl.1): S47-54.

[20] Tichy L, Freiberg T, Zapletalov $P$, et al. The molecular basis offamilial cholesterolemia in Czech Republic: spetrum of LDLR mutations and genotype-phenotype corrrelations. Atherosclerosis 2012; 223: 401-8. https://doi.org/10.1016/j.atherosclerosis.2012.05.014
[21] Phillips KM, Ruggio DM, Bailey JA. Precise quantitative determination of phytosterols, stenols, and cholesterol metabolites in human serum, by capillary gas-liquid chromatography. J Chromatog 1999; B732: 17-29.

[22] Theunissen CE, Regente J, Bergman K, et al. Serum cholesterol precursors and metabolites and cognitive performace in an aging population. Neurobiol Aging 2003; 24: $147-155$. https://doi.org/10.1016/S0197-4580(02)00061-1

[23] Hyanek J, Dubska L, Martinikova V, et al. The influence of menarche on high cholesterol level in adolescent girls with familial hypercholesterolemia. Čs Slov Pediat 2013; 68: 1218. (in Czech with English summary).

[24] MacKay DS, Jones PJH. Plasma noncholestero sterols:corrent uses potential and need for standardization. Curr Opin Lipidol 2012; 23: 241-47. https://doi.org/10.1097/MOL.0b013e328353292e

[25] MacKay DS, Jones PJH. Evaluation of methods for the determination of cholesterol absorption and synthesis in humans. Atherosclerosis 2001; 218: 253-62. https://doi.org/10.1016/j.atherosclerosis.2010.04.022

[26] Sutherland WHF, Williamns MJA, Nye NJ, Restieaux NJ, deJong SA, Walker HL. Associations of plasma noncholesterol sterol levels with severity of coronary artery disease. Nutr Metab Cardiovasc Dis 1998; 8: 389-391.

[27] Sudhop T, Reber M, Tribble D, et al. Changes in cholestero absorption and cholesterol synthesis caused by ezetimibe and/or simvastatin in men. J Lipid Res 2009; 50: 2117-2123. https://doi.org/10.1194/jlr.P900004-JLR200

[28] Lupatelli G, Pirro M, Siepi D, et al. Non-cholesterol sterols in different forms of primary hyperlipemias. Nutr Metab Cardiovasc Dis 2012; 22: 231-6. https://doi.org/10.1016/j.numecd.2010.05.010

[29] Miettinen TA, Gylling H, Nissinen MJ. The role of serum noncholesterol sterols as surrogate markers of absolute cholesterol synthesis and absorption. Nutr Metab Cardiovasc Dis 2011; 21: 765-769. https://doi.org/10.1016/j.numecd.2011.05.005 